\title{
Potential Pathogens among Fungi Identified as Nonsporulating Molds from Blood Cultures
}

\author{
Mohd Fuat Abd Razak*, Parameswari Sabaratnam, Rahizan Issa \\ Infectious Diseases Research Centre, Institute for Medical Research, Kuala Lumpur, Malaysia \\ Email: fuat@imr.gov.my
}

Received 22 July 2015; accepted 9 October 2015; published 12 October 2015

Copyright (C) 2015 by authors and Scientific Research Publishing Inc.

This work is licensed under the Creative Commons Attribution International License (CC BY). http://creativecommons.org/licenses/by/4.0/

(c) (i) Open Access

\section{Abstract}

Twenty-eight molds were isolated from clinical blood cultures and were unidentifiable by cellular morphology using conventional microscopy. Using the utility of amplification and direct sequencing of internal transcribed spacer region of ribosomal RNA gene, $93 \%$ of these fungi were identified. Seventy-one percents of the molds were found to be associated with plants or soil with no or few published cases of human disease. These include species of basidiomycetes and ascomycetes such as Botryosphaeria dothidea, Phomopsis flavodonflavus, Inonotus pachyphloeus, Earlilella scabrosa, Calocybe indica, Athelia pellicularis, Tinctoporellus epimiltinus, Trametes lactinea, Coprinellus aureogranulat and Xylaria feejeensis. Some of the nonsporulating molds were identified as pathogen or potential pathogens in immunocompetent or immunocompromised hosts. These include Schizophylum commune and hyphomycetes such as Cladosporium cladosporoides, Aspergillus niger and Fusarium equiseti. Basidiomycetes and hyphomycetes identified in the current study are ubiquitous in the environment and are almost similar to the species of molds reported from cutaneous and respiratory samples suggesting that the fungi may represent contaminants rather than true fangaemia. Results of this study emphasize the need of an effort to minimise blood culture contamination and support the recommendation to incorporate clinical, radiologic findings and positive blood culture for molds in the diagnosis and management of invasive mycosis.

\section{Keywords}

Blood Cultures, Fungi, Nonsporulating Molds, Basidiomycetes

\footnotetext{
${ }^{*}$ Corresponding author.
}

How to cite this paper: Abd Razak, M.F., Sabaratnam, P. and Issa, R. (2015) Potential Pathogens among Fungi Identified as Nonsporulating Molds from Blood Cultures. Journal of Biosciences and Medicines, 3, 39-44. 


\section{Introduction}

The incidence of fungal infections by filamentous fungi (molds) is increasing especially among immunocompromised patients. While Aspergillus, Zygomycetes and Fusarium are the most commonly recognized molds, there are large and heterogenous group of molds that are capable causing infection in both immunocompromised and immunocompetant patients. Thus, accurate diagnosis of the causative agents is essential before initiation of antifungal therapy.

Culturing clinical specimens for fungus in the diagnosis of fungal infection is still a gold standard in clinical mycology laboratory. Molds isolated from a positive direct microscopy of clinical specimens are always significant isolates. However, fungal elements in clinical specimens are sparse. Thus, isolation of molds from negative direct microscopy specimen does not rule out fungal infection. It is not uncommon that many clinical mycology laboratories do not perform direct microscopy observation on the clinical specimens.

Molds that grow from clinical specimens are identified by characterizing the reproductive spore under microscope. A mold cannot be identified by microscopic morphology if it does not sporulate in culture media within 2 - 3 weeks. Laboratories report these fungi to clinicians as mycelium sterila or nonsporulating mould (NSM). These reports are rather inconclusive but most clinicians would not treat patient if the NSM are isolated from superficial, cutaneous or respiratory specimens.

In recent years, DNA-based methods have been developed and played a role as adjunctive tool for the identification of pathogenic fungi in certain reference laboratories. Amplification by polymerase-chain-reaction (PCR) and sequencing of the internal transcribed spacer (ITS) regions I and II in the ribosomal RNA operon of fungi have been found to have sequence variability and have been used to identify fungi to species level [1] including NSM [2] [3].

Nonsporulating molds have been isolated and reported from superficial, cutaneous and respiratory tract specimens [4]. To our knowledge no study has attempted to classify NSM fungi associated with systemic clinical samples such as blood. Unlike superficial and cutaneous fungal infections, systemic infections can be lifethreatening especially in the immunocompromised patients. Blood samples are the most common clinical samples sent to pathological laboratories to determine systemic fungal infection. The aim of this study was to determine the identity of NSM isolated from clinical blood samples by sequencing of ITS regions in order to detect clinically significant pathogens among these previously unidentifiable fungi.

\section{Materials and Methods}

\subsection{Fungal Isolates}

Mycology laboratory in Institute for Medical Research, Kuala Lumpur, Malaysia, has been a reference laboratory for identification of fungus isolated from clinical specimens. In 2013, the laboratory received 955 fungal isolates for identification from various hospitals in Malaysia. In the laboratory, the mould submitted as an isolated culture, was first grown on Sabouraud agars (Oxoid), Cornmeal agar (Merck) and Malt extract agar (Oxoid). Microscopic cellular structures were then observed on standard tease slide preparation for up to 21 days. The culture was also grown on Potato-dextrose agar (Oxoid) using the standard slide culture method and sporulation was observed for up to 21 days. Nonsporulating molds were confirmed after the filamentous fungus failed to form any sexual or asexual spores on the media. Out of 955 fungal isolates received, 112 were NSM (32.5\%) and 28 of the NSM were from fungal blood culture bottles of automatic blood culture system such as BACTEC. All 28 NSM isolates were grown on Potato dextrose agar for gene amplification and sequencing.

\subsection{DNA Extraction}

All chemicals and reagents used in the DNA extraction were purchased from Qiagen (Germany). After growth for 7 days on Potato dextrose agar slants, approximately $1 \mathrm{~cm}^{2}$ of NSM fungal mycelia were scraped into $500 \mu \mathrm{l}$ PBS and centrifuged at 18,000 g for $1 \mathrm{~min}$. The supernatant was removed and tissue lysis buffer and proteinase $\mathrm{K}$ were added followed by incubation at $55^{\circ} \mathrm{C}$ for $18 \mathrm{~h}$. Lyticase was added and the reaction mixture was incubated at $37^{\circ} \mathrm{C}$ for $1 \mathrm{~h}$. The genomic DNA was then extracted and isolated using QIA quick PCR Purification Kit (Qiagen, Germany) according to the manufacturer's instructions.

\subsection{Polymerase-Chain Reaction and DNA Sequencing}

Polymerase-Chain-Reaction (PCR) was performed using primers ITS1 and ITS4 purchased from Intergrated 
DNA Technologies Inc. (IDT, USA). All chemicals and reagents for PCR and preparation of DNA for sequencing were purchased from Qiagen (Germany). A $25 \mu$ l-PCR mixture was prepared as follows: $2.5 \mu 1$ 10× PCR buffer with final $\mathrm{MgCl}_{2}$ concentration of $1.5 \mathrm{mM}, 0.5 \mu \mathrm{l}$ of $0.2 \mathrm{mM}$ deoxynucleoside triphosphates, $0.25 \mu \mathrm{l}$ each of the forward and reverse primers, $5 \mu \mathrm{l}$ template DNA, $0.125 \mu \mathrm{l}$ Qiagen Hotstar Taq polymerase $\left(5 \mathrm{U} \cdot \mu \mathrm{l}^{-1}\right)$ and molecular biology grade $\mathrm{H}_{2} \mathrm{O}$ was added to a total volume of $25 \mu \mathrm{l}$. Amplifications were carried out in thermocycler with the following thermal cycling parameters: initial denaturation at $95^{\circ} \mathrm{C}$ for $5 \mathrm{~min}$, followed by heat denaturation at $94^{\circ} \mathrm{C}$ for $1 \mathrm{~min}$, annealing at $58^{\circ} \mathrm{C}$ for $1 \mathrm{~min}$, extension at $72^{\circ} \mathrm{C}$ for $1 \mathrm{~min}$ and final extension at $72^{\circ} \mathrm{C}$ for $10 \mathrm{~min}$. Ten microlitre PCR products were sent to 1st BASE Laboratories, Kuala Lumpur, for sequencing. The sequences were then identified using the BLAST program (http://www.ncbi.nlm.nih.gov). Sequence-based identifications were defined by percent identity: species, $\geq 99 \%$; genus, $94 \%$ - $98 \%$; and inconclusive, $\leq 93 \%$. Molds were classified as fungi often associated with clinical disease (pathogens), fungi with more than three cases reported (potential pathogens), or plant/soil-associated fungi with no published cases of human disease [4].

\section{Results}

Table 1 shows the identification of the 28 NSM isolates. Twenty-six isolates (93\%) were identified to at least genus (19 isolates were identified to species) while 2 being inconclusive. Twenty different genera of molds were

Table 1. Identification of nonsporulating molds from blood cultures by gene amplification and sequencing of ITS region.

\begin{tabular}{|c|c|c|c|c|c|}
\hline $\begin{array}{l}\text { Culture } \\
\text { code }\end{array}$ & Closest BLAST match & Identity (\%) & $\begin{array}{c}\text { GenBank } \\
\text { Accession No. }\end{array}$ & $\begin{array}{l}\text { No. of species with } \\
\geq 99 \% \text { homology }\end{array}$ & $\begin{array}{l}\text { Microorganism } \\
\text { classification }\end{array}$ \\
\hline 123 & Nigrospora spp & 100 & HQ248210 & 2 & Plant/soil \\
\hline 175 & Fusarium equiseti & 99 & HO718414 & 4 & Potential pathogen \\
\hline 177 & Schizophylum commune & 100 & AF350925 & 1 & Pathogen \\
\hline 216 & Xylariaceae spp. & 100 & JN418798 & 2 & Plant/soil \\
\hline 263 & Cladopsporium cladosporoides & 99 & EU645693 & 2 & Pathogen \\
\hline 270 & Botryosphaeria dothidea & 99 & AY626347 & 4 & Plant/soil \\
\hline 277 & Phomopsis longicolla & 100 & FJ478126 & 0 & Plant/soil \\
\hline $293-2$ & Pseudozyma churashimaensis & 97 & AB548943 & 0 & Plant/soil \\
\hline 313 & Aspergillus niger & 99 & AM745113 & 1 & Pathogen \\
\hline $357-2$ & Inonotus pachyphloeus & 98 & AY558635 & 0 & Plant/soil \\
\hline $460-2$ & Earliella scabrosa & 98 & JN165006 & 0 & Plant/soil \\
\hline 562 & Aspergillus oryzae & 100 & AKXL01000280 & 3 & Potential pathogen \\
\hline 603 & Calocybe indica & 88 & GQ259881 & 0 & Plant/soil \\
\hline 662 & Flavodon flavus & 100 & FJ478126 & 2 & Plant/soil \\
\hline 710 & Tinctoporellus epimiltinus & 98 & GU731575 & 0 & Plant/soil \\
\hline 739 & Trametes lactinea & 98 & HM756193 & 0 & Plant/soil \\
\hline $340 / 12$ & Aspergillus sydowii & 98 & HO889716.1 & 0 & Potential pathogen \\
\hline 340 & Pseudozyma spp. & 99 & AM176732 & 3 & Potential pathogen \\
\hline 809 & Cerrena spp. & 99 & FJ010208 & 2 & Plant/soil \\
\hline 810 & Coprinellus aureogranulatus & 99 & GO249274 & 1 & Plant/soil \\
\hline 811 & Entomocorticium spp. & 94 & DO118417 & 0 & Plant/soil \\
\hline 813 & Fomitopsis ostreiformis & 100 & FJ372684 & 3 & Plant/soil \\
\hline 876 & Penicillium spp. & 97 & HM773242 & 0 & Plant/soil \\
\hline 903 & Schizophyllum commune & 99 & FJ478109 & 3 & Pathogen \\
\hline 977 & Pseudozyma parantarctica & 99 & AB089356 & 1 & Potential pathogen \\
\hline 983 & Coriolopsis polyzona & 99 & FJ627248 & 1 & Plant/soil \\
\hline 1023 & Eutypella scoparia & 84 & EU436688 & 0 & Plant/soil \\
\hline 1056 & Xylaria feejeensis & 98 & GU322454 & 0 & Plant/soil \\
\hline
\end{tabular}


conclusively identified. Fifteen of the 28 isolates were basidiomycetes which include Botryosphaeria dothidea, Phomopsis flavodonflavus, Inonotus pachyphloeus, Earlilella scabrosa, Calocybe indica, Athelia pellicularis, Tinctoporellus epimiltinus, Trametes lactinea, and Coprinellus aureogranulata. Seven isolates were hyphomycetes such as Cladosporium cladosporoides, Aspergillus niger, Aspergillus sydowii, Aspergillus oryzae, Fusarium equisettii, Nigrospora species and Penicillium species. Six ascomycetous fungi such as Xylaria feejeensis, Phomopsis longicolla and Pseudozyma were also identified.

\section{Discussion}

Majority of molds grew in the blood cultures (71\%) were associated with plants or soil with no published cases of human disease. These include filamentous basidiomycetes such as Botryosphaeria dothidea, Phomopsis flavodonflavus, Inonotus pachyphloeus, Earlilella scabrosa, Calocybe indica, Athelia pellicularis, Tinctoporellus epimiltinus, Trametes lactinea, and Coprinellus aureogranulata, and ascomycetes such as Xylaria feejeensis and Phomopsis longicolla. However, there are more than 70 reported cases of human infection (mostly through respiratory tract) by the basidiomycetous fungi Schizophylum commune [5]. Invasive infections of the lung, brain and palate in immunocompromised and immunocompetent patients have been described [6].

Basidiomycetes have been known not to produce recognizable spores on mycological media commonly used for culturing medically important fungi such as Sabaouraud dextrose agar, Malt extract agar and Potato dextrose agar. Microscopic examination revealed hyaline, septate hyphae without any particular features. Some isolates showed clamp connections which indicate it belongs to Basidiomycetes. The presence of clamp connections and lateral, short, thin truncate hyphal tubercles are diagnostic of S. commune. However, clamp connections and truncate hyphal tubercle may be overlooked or may not develop in certain isolates [7]. Isolation of Pseudozyma parantarctica in blood samples was first reported in 2003 and there has been no report of human infection by $P$. churashimaensis. More than 10 species of Pseudozyma have been described to-date. However, human infections have been more frequently associated with P. aphidis than any other species of Pseudozyma. Pseudozyma aphidis has recently been implicated in potentially fatal disorders ranging from subcutaneous mycoses to disseminated infections [8].

Although reports on human infections by hyphomycetes Cladosporium cladosporoides are rare, C. cladosporoides were reported as etiologic agents of systemic phaeohyphomycosis in immunocompetent [9]. Aspergilli normally sporulate on Sabaouraud agar or Malt extract agar but were observed as hyaline mycelium in the current study. Reports on nonsporulating Aspergilli were not uncommon [2]. Three species of Aspergillus were identified from the blood cultures but only A. niger could be considered as pathogen especially in otitis media and cutaneous infections. Aspergillus niger is considered to be a fungus of low virulence and was not frequently implicated in invasive disease in immunocompetent patients. The advent of organ transplants and immunosuppressive therapy has shown that Aspergillus niger has the ability to initiate invasive disease in this group of patients [10]. A. sydowii and A. oryzae may cause invasive infection in those with more profound immunosuppression [11]. When not sporulating on medical mycology laboratory growth media, hyphomycetes will be observed as septate hyaline or dematiacous mycelium without any particular features.

Despite method such as PCR may lead to the identification of the NSM, the significance of isolation of the NSM need to be confirmed. Rate of isolation of filamentous molds in commercial blood culture systems that represented true fungemia has been very low and involved fungi mostly in the genera of Fusarium and Aspergillus [12]. Molds other than Fusarium and Aspergillus spp. represented 1\% of all positive fungal blood cultures in a study of 185,000 blood cultures [13]. The blood culture growth medium was found not supportive for growth of many molds including some common hyphomycetes such as Penicillium species, Exophiala dermatidis, Phialophora verrucosa, Acremonium species and Alternaria alternata [14]. It may also not supportive for growth of basidiomycetes as little or no reports on basidiomycetes were isolated from blood cultures. Numerous reports on systemic infections by basidiomycetes and other filamentous molds showed that blood cultures were mostly negative and infections were detected by radiographic procedures [15] [16]. Most laboratories withdraw some culture broth using hypodermic syringe from blood culture detected for growth by BACTEC machine and culture this broth onto growth agar media. However, NSM are not likely to be grown on subculture from culture broth withdrawn with hypodermic syringe because clumps of mycelium would not rapidly travel down into the neck of the bottle when inverted. As such, no hyphae would be drawn out during the subculture of the blood onto solid media [14] [17]. In a report, growth of filamentous fungi in blood culture was confirmed by visualization 
of hyphae in the culture broth after repeated subcultures of culture broth on agar plates yielded no growth [18].

Although S. commune, C. cladosporoides and A. niger are pathogenic and clinically significant pathogenic fungi, these fungi and all other basidiomycetes, ascomycetes and hyphomycetes identified in the current study are ubiquitous in the environment and are almost similar to the species of NSM reported from cutaneous and respiratory samples elsewhere [3] [4] suggesting that the fungi may represent contaminants rather than true fungaemia. Contaminant fungi may be introduced into blood culture bottle from blood samples (contaminants on the skin or sampling devices), inoculation of blood sample into blood culture bottle through rubber septum and during subculture of culture broth from blood culture bottle onto Mycological growth media such as Brainheart-infusion agar (laboratory contaminants) after positive growth signal was detected by the BACTEC machine. Even though aspergillemia is one of the most common invasive filamentous molds infections and have been detected by blood culture, a study on 300,000 blood samples in wards of cancer patients showed that majority of Aspergilli isolated from these patients (solid tumours and hematologic malignancies) represented contamination [19]. In a study of high-risk patients including cancer patients, $70 \%$ of the positive blood cultures for molds were false-positive [13].

In the past decade, filamentous basidiomycetes have been reported as invasive pathogens in immunosuppressed patients, such as patients with hematological malignancies and solid-organ transplant recipients. Furthermore, the resistance to amphotericin B reported for some NSM emphasizes the need for minimizing the rate of false-positive blood culture. Eliminating sources of blood culture contamination requires an effort of both laboratory and ward personnel. Aseptic techniques should be strictly adhered in sampling and inoculating blood samples into blood culture bottles. There is a need for a good quality control of mycological media and inoculating devices including biosafety cabinet. Laboratory personnel should from time to time determine the load of fungal spores and the most common contaminants in the laboratory. They should be cautious if the same species of environmental fungi including NSM was isolated from several blood cultures. The European Organization for Research and Treatment of Cancer incorporate clinical, radiologic, microscopic and culture results in the diagnosis and management of systemic infections associated with filamentous fungi [20]. These criteria are recommended in the cases of positive blood cultures associated with NSM.

\section{Conclusion}

Results of the current study show that all NSM isolated from the blood cultures were environmental fungi with only 3 species having been reported to be pathogenic. Species of the NSM were similar to most NSM identified from cutaneous and respiratory specimens and isolation of these isolates may not reflect true fungemia.

\section{Acknowledgements}

We thank the Director-General of Health, Malaysia, for permission to publish. Thanks are also due to the Director of Institute for Medical Research (IMR) for support. This research was supported by grants from Ministry of Health Malaysia [Grant number: JPP-IMR Non-Cam 07-027].

\section{References}

[1] Borman, A.M., Christopher, J.L., Sarah, J.M. and Elizabeth, M.J. (2008) Molecular Identification of Pathogenic Fungi. Journal of Antimicrobial Chemotherapy, 61, i7-i12. http://dx.doi.org/10.1093/jac/dkm425

[2] Callister, M.E., Griffiths, M.J., Nicholson, A.G., Leonard, A., Johnson, E.M., Polkey, M.I. and Kerr, J.R. (2004) Fatal Case of Disseminated Aspergillosis Caused by a Nonsporulating Strain of Aspergillus fumigatus. Journal of Clinical Pathology, 57, 991-992. http://dx.doi.org/10.1136/jcp.2003.014449

[3] Singh, P.K., Kathuria, S., Agarwal, K., Gaur, S.N., Meis, J.F. and Chowdhary, A. (2013) Clinical Significance and Molecular Characterization of Nonsporulating Molds Isolated from the Respiratory Tracts of Bronchopulmonary Mycosis Patients with Special Reference to Basidiomycetes. Journal of Clinical Microbiology, 51, 3331-3337. http://dx.doi.org/10.1128/JCM.01486-13

[4] Pounder, J.I., Keith, E.S., Claudia, A.B., Sheri, L.H., Mary, E.B. and Cathy, A.P. (2007) Discovering Potential Pathogens among Fungi Identified as Nonsporulating Moulds. Journal of Clinical Microbiology, 45,568-571. http://dx.doi.org/10.1128/JCM.01684-06

[5] Chowdhary, A., Randhawa, H.S., Gaur, S.N., Agarwal, K., Kathuria, S., Roy, P., Klaassen, C.H. and Meis, J.F. (2013) Schizophyllum commune as an Emerging Fungal Pathogen: A Review and Report of Two Cases. Mycoses, 56, 1-10. 
http://dx.doi.org/10.1111/j.1439-0507.2012.02190.x

[6] Sigler, L. (2003) Miscellaneous Opportunistic Fungi. In: Howard, D.H., Ed., Pathogenic Fungi in Humans and Animals, Marcel Dekker, Inc., New York, 637-676.

[7] Buzina, W., Lang-Loidolt, D., Braun, H., Freudenschuss, K. and Stammberger, H. (2001) Development of Molecular Methods for Identification of Schizophyllum commune from Clinical Samples. Journal of Clinical Microbiology, 39, 2391-2396. http://dx.doi.org/10.1128/JCM.39.7.2391-2396.2001

[8] Prakash, A., Wankhede, S., Singh, P.K., Agarwal, K., Kathuria, S., Sengupta, S., Barman, P., Meis, J.F. and Chowdhary, A. (2014) First Neonatal Case of Fungaemia Due to Pseudozyma aphidis and a Global Literature Review. Mycoses, 57, 64-68. http://dx.doi.org/10.1111/myc.12098

[9] Aglawe, V., Tamrakar M, Singh, S.M. and Sontakke, H. (2013) Systemic Phaeohyphomycosis Caused by Cladosporium cladosporioides: In Vitro Sensitivity and Its Serological Diagnosis. Advanced in Life Sciences \& Technology, 8, 16-21.

[10] Patterson, T.F., Kirkpatrick, W.R., White, M., Hiemenz, J.W., Wingard, J.R., Dupont, B., Rinaldi, M.G., Stevens, D.A. and Graybill, J.R. (2000) Invasive Aspergillosis: Disease Spectrum, Treatment Practices, and Outcomes. I3 Aspergillus Study Group. Medicine (Baltimore), 79, 250-260. http://dx.doi.org/10.1097/00005792-200007000-00006

[11] Torres, H.A., Rivero, G.A., Lewis, R.E., Hachem, R., Raad, I.I. and Kontoyiannis, D.P. (2003) Aspergillosis Caused by Non-Fumigatus Aspergillus Species: Risk Factors and in Vitro Susceptibility Compared with Aspergillus fumigatus. Diagnostic Microbiology \& Infectious Diseases, 46, 275-286. http://dx.doi.org/10.1016/s0732-8893(03)00013-0

[12] Morrell, R.M., Wasilauskas, B.L. and Steffee, A.H. (1996) Performance of Fungal Blood Cultures by Using the Isolator Collection System: Is It Cost-Effective? Journal of Clinical Microbiology, 34, 3040-3043.

[13] Lionakis, M.S., Bodey, G.P., Tarrand, J.J., Raad, I.I. and Kontoyiannis, D.P. (2004) The Significance of Blood Culture Positive for Emerging Saprophytic Molds in Cancer Patients. Clinical Microbiology and Infectious Diseases, 10, 922925. http://dx.doi.org/10.1111/j.1469-0691.2004.00933.x

[14] Breathnach, A. and Evans, J. (1995) Growth and Detection of Filamentous Fungi in the BacT/Alert Blood Culture System. Journal of Clinical Pathology, 48, 670-672. http://dx.doi.org/10.1136/jcp.48.7.670

[15] Campa-Thompson, M.M., West, J.A., Guileyardo, J.M., Spak, C.W., Sloan, L.M. and Beal, S.G. (2014) Clinical and Morphologic Findings in Disseminated Scedosporium apiospermum Infections in Immunocompromised Patients. Baylor University Medical Centre Proceedings, 27, 253-256.

[16] Verweij, P.E., van Kasteren, M., van de Nes, J., de Hoog, G.S., de Pauw, B.E. and Meis, J.F. (1997) Fatal Pulmonary Infection Caused by the Basidiomycete Hormographiella aspergillata. Journal of Clinical Microbiology, 35, 675-678.

[17] Rosa, C., Araujo, R., Rodrigues, A.G., Pinto-de-Sousa, M.I. and Pina-Vaz, C. (2011) Detection of Aspergillus Species in BACTEC Blood Cultures. Journal of Medical Microbiology, 60, 1467-1471. http://dx.doi.org/10.1099/jmm.0.030601-0

[18] Dien, B.J., Mangahis, A., Hofstrac, T.C. and Bender, J.M. (2014) First Case Report of Bloodstream Infection by Rhizomucor pusillus in a Child with Hemophagocytic Lymphohistiocytosis. Medical Mycology Case Reports, 5, 20-23. http://dx.doi.org/10.1016/j.mmcr.2014.05.002

[19] Kontoyiannis, D.P., Sumoza, D., Tarrand, J., Bodey, G.P., Storey, R. and Raad, I.I. (2000) Significance of Aspergillemia in Patients with Cancer: A 10-Year Study. Clinical Infectious Diseases, 31, 188-189. http://dx.doi.org/10.1086/313918

[20] Ascioglu, S., Rex, J.H., de Pauw, B., et al. (2002) Defining Opportunistic Invasive Fungal Infections in Immunocompromised Patients with Cancer and Hematopoietic Stem Cell Transplants: An International Consensus. Clinical Infectious Diseases, 34, 7-14. http://dx.doi.org/10.1086/323335 